\title{
Tau Imaging in Neurodegenerative Diseases Using Positron Emission Tomography
}

\author{
Yi Ting Wang ${ }^{1} \cdot$ Paul Edison ${ }^{1,2}$
}

Published online: 6 June 2019

(C) The Author(s) 2019

\begin{abstract}
Purpose of Review Abnormal accumulation of tau protein is the main hallmark of tauopathies and is closely associated with neurodegeneration and cognitive impairment, whereas the advance in PET imaging provides a non-invasive detection of tau inclusions in the brain. In this review, we discuss the potential of PET imaging as a biomarker in tauopathies, the latest development of novel tau tracers with new clinical information that has been disclosed, and the opportunities for improving diagnosis and designing clinical trials in the future.

Recent Findings In recent years, several first-generation tau PET tracers including $\left[{ }^{11} \mathrm{C}\right] \mathrm{PBB} 3,\left[{ }^{18} \mathrm{~F}\right] \mathrm{THK}-5117,\left[{ }^{18} \mathrm{~F}\right] \mathrm{THK}-5351$ and $\left[{ }^{18} \mathrm{~F}\right] \mathrm{AV}-1451$ have been developed and succeeded in imaging neurofibrillary pathology in vivo. Due to the common offtarget binding and subcortical white matter uptake seen in the first-generation tracers, several research institutes and pharmaceutical companies have been working on developing second-generation tau PET tracers which exhibit higher binding affinity and selectivity.

Summary Tau PET imaging is promising to serve as a biomarker to support differential diagnosis and monitor disease progression in many neurodegenerative diseases.
\end{abstract}

Keywords Positron emission tomography $\cdot$ Tau $\cdot$ Neurofibrillary tangles $\cdot$ Dementia $\cdot$ Neurodegenerative diseases Neurodegeneration

\section{Introduction}

Neurofibrillary tangles (NFTs) are one of the primary hallmarks of Alzheimer's disease (AD), along with amyloid plaques, cerebral amyloid angiopathy and glia activation [1]. NFTs are aggregates of hyperphosphorylated tau protein and they form before the clinical symptoms of AD manifest. The amount of NFTs was reported to be tightly linked to the severity of AD-type dementia, suggesting that they are better

This article is part of the Topical Collection on Neuroimaging

Paul Edison

paul.edison@imperial.ac.uk

1 Neurology Imaging Unit, Division of Brain Sciences, Department of Medicine, Imperial College London, 1st Floor B Block,

Hammersmith Hospital Campus, Du Cane Road, London W12 0NN, UK

2 Cardiff University, Cardiff CF10 3AT, UK correlated with neuronal dysfunction [2]. Cortical density of hyperphosphorylated tau tangles in $\mathrm{AD}$ postmortem brain also correlates with pre-morbid cognitive dysfunction and neuronal loss [3]. It is important to note that besides $\mathrm{AD}$, accumulation of tau protein is observed in numerous other diseases known as tauopathies. Tauopathies is the term used to describe a group of neurodegenerative conditions characterised by the abnormal accumulation of tau aggregates in the brain. Along with $\mathrm{AD}$ and some variants of frontotemporal lobe degeneration (FTLD), other tauopathies include Pick's disease, frontotemporal dementia with parkinsonism linked to chromosome-17 (FTDP-17), progressive supranuclear palsy (PSP), corticobasal degeneration (CBD) and chronic traumatic encephalopathy (CTE) [4]. Although all these disorders share tau immunoreactivity in postmortem analysis, they can be composed of different tau isoforms and show distinct histopathological differences [5].

There are six isoforms of tau expressing in adult human central nervous system resulting from the alternative splicing of pre-mRNA generated from microtubule-associated protein tau (MAPT) gene. These tau isoforms can contain either three 
or four microtubule-binding repeats, termed 3R-tau or 4R-tau respectively. Tau protein isoforms in the human brain are demonstrated in Fig. 1 [6].

Under normal physiological condition, 3R-tau and 4R-tau are expressed at similar level; however, in the brains in several tauopathies, the 3R-tau/4R-tau ratio is altered [7]. Comparison of the tau aggregates in different neurodegenerative disorders reveals high diversity in both the degree of phosphorylation and the content of the different tau isoforms. This could possibly explain the variation in tau inclusion morphology and cellular specificity. Tauopathies, as a result, may be subdivided into disorders with inclusions made predominantly of 3R- or 4R-tau or a combination of both [8]. A brief molecular pathological classification of tauopathies is summarised in Table 1.

Among the main pathophysiological hallmarks of $\mathrm{AD}$, NFTs have a stereotypical spatiotemporal progression that correlates better with the severity of the cognitive decline seen in the disease compared to $A \beta$ plaques [1]. NFTs start in the allocortex of the medial temporal lobe (entorhinal cortex and hippocampus) and spreads to the associative neocortex, relatively sparing the primary sensory, motor and visual areas. In Braak staging of AD, NFTs first appear in the perirhinal region along with the entorhinal cortex (stage I), followed by the CA1 region of the hippocampus (stage II). NFTs later develop and accumulate in the limbic structures such as the hippocampal formation (stage III) and the amygdala, thalamus and claustrum (stage IV). Eventually, NFTs spread to all neocortical areas, with the association areas being affected prior and more severely (stage $\mathrm{V}$ ) than the primary sensory, motor and visual areas (stage VI) [9]. Thus, biomarkers for tau pathology are considered promising and essential to the research criteria in the pathological diagnosis of $\mathrm{AD}$.

\section{PET Imaging as a Biomarker in Tauopathies}

The advance in molecular imaging has shed light on the use of imaging biomarker in the diagnosis of $\mathrm{AD}$ as well as many other neurodegenerative diseases. Positron emission tomography (PET) is a non-invasive diagnostic imaging modality utilising isotope-labelled molecular probes that bind to molecules with both high specificity and affinity. In recent years, several PET tracers targeting abnormal conformations of the tau protein have been developed, which allowed researchers to visualise tau aggregate in vivo [10]. As tau is a complex protein with multiple isoforms and post-translational modifications, tau PET tracers may bind to specific or multiple isoforms. Moreover, since tau is an intracellular protein, these radioligands will need to possess the ability to cross the plasma cell membranes as well as the blood-brain barrier (BBB). Tau aggregates are coexistent with $A \beta$ plaques which both share $\beta$-sheet structure in human $\mathrm{AD}$, even though it is 5 to 20 times lower concentrations than $A \beta$ plaques [11]. This suggests that the radioligands need to be highly selective with at least 10 -fold higher binding affinity for tau compared with $\mathrm{A} \beta$ [3]. To date, several PET ligands including $\left[{ }^{11} \mathrm{C}\right] \mathrm{PBB} 3$, $\left[{ }^{18} \mathrm{~F}\right]$ THK5105, $\left[{ }^{18} \mathrm{~F}\right]$ THK5117, $\left[{ }^{18} \mathrm{~F}\right]$ THK5351 $\left[{ }^{18} \mathrm{~F}\right] \mathrm{T} 807$ and $\left[{ }^{18} \mathrm{~F}\right] \mathrm{T} 808$ have been tested to image tau neurofibrillary tangle deposition in living AD patient brains [12-14, 15••]. Some of these tau PET tracers are considered superior to others and are now available for clinical assessment of patients with various tauopathies, including $\mathrm{AD}$, as well as in healthy subjects. They provide the opportunity of in vivo topographical distribution and quantification of tau aggregates in the early phases of neurodegenerative diseases, in parallel with clinical and cognitive assessments. As such, tau imaging is considered of key importance for progress toward earlier and more accurate diagnosis of tauopathies as well as for the tracking of disease progression, monitoring therapeutic interventions and drug development.

In this review, we examine both preclinical and clinical PET studies of the first-generation tau PET tracers, discussing the promising usefulness and the difficult challenges, as well as the opportunities for tau PET imaging used to improve diagnosis and help designing clinical trials. We further

Exons

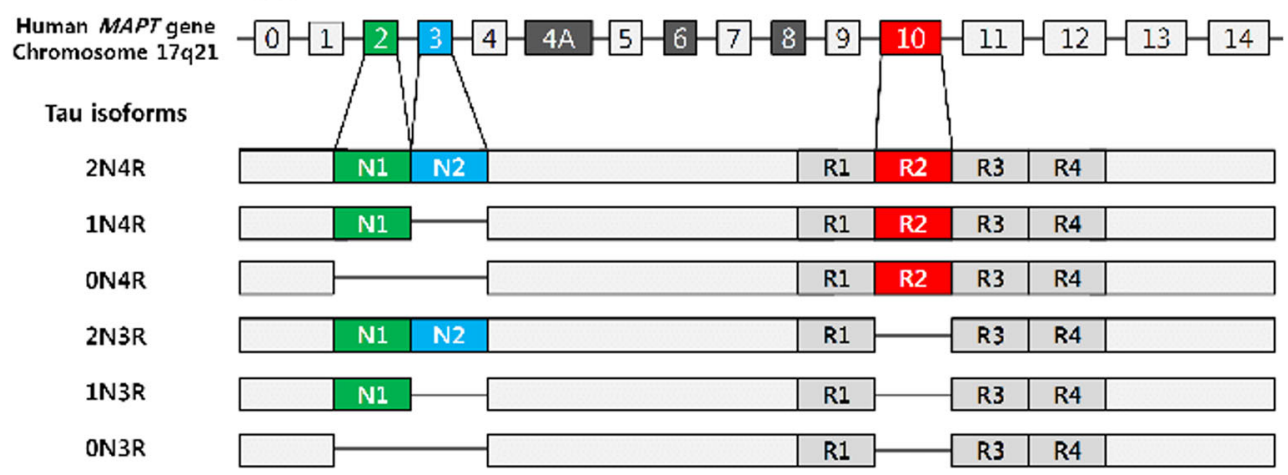

Fig. 1 Tau protein isoforms in the human CNS. Six tau isoforms are present in the brain. N1 (green) and N2 (blue) are produced through the alternative splicing of exons 2 and 3 respectively. Exon 10 encodes the second aspect of the microtubule-binding repeat domain, R2 (red).

Depending on the presence of the $\mathrm{R} 2$ domain, tau proteins are termed either 3R-tau or 4R-tau. (Figure used with permission from BMB Rep. Park SA, Ahn SI, Gallo J-M. Tau mis-splicing in the pathogenesis of neurodegenerative disorders. BMB Rep. 2016;49:405-413) 
Table 1 Pathological classification of Tauopathies

\begin{tabular}{|c|c|c|c|}
\hline $\begin{array}{l}\text { Predominant tau } \\
\text { isoforms }\end{array}$ & 3R-tau & 4R-tau & 3R- \& 4R-tau \\
\hline \multirow[t]{5}{*}{ Disorders } & - Pick's disease (PiD) & • PSP & $\begin{array}{l}\text { - NFT dementia (including } \\
\text { AD) }\end{array}$ \\
\hline & • FTLD-MAPT & - $\mathrm{CBD}$ & • PART \\
\hline & \multirow{3}{*}{$\begin{array}{l}\text { - FTDP-17 with } \\
\text { 3R-tau }\end{array}$} & - AGD & • CTE \\
\hline & & • GGT & - FTLD-MAPT \\
\hline & & $\begin{array}{l}\text { - FTLD-MAPT } \\
\text { - FTDP-17 with } \\
\quad \text { 4R-tau }\end{array}$ & - FTDP-17 with 3R- \& 4R-tau \\
\hline
\end{tabular}

3R-tau: tau protein isoform with 3 repeats in the microtubule-binding domain; 4R-tau: tau protein isoform with 4 repeats in the microtubule-binding domain; 3R- \& 4R-tau: mixed 3 and 4 repeat tau protein isoforms

$P S P$ progressive supranuclear paralysis, $C B D$ corticobasal degeneration, $A G D$ argyrophilic grain disease, $G G T$ globular glial tauopathy, CTE chronic traumatic encephalopathy, PART primary age-related tauopathy, FTLD$M A P T$ Frontotemporal lobar degeneration associated with mutations in MAPT demonstrate new clinical information that has been uncovered regarding newly developed novel second-generation tau tracers.

\section{First-Generation Tau Tracers}

\section{$\left[{ }^{18}\right.$ F]FDDNP}

2-(1-\{6-[(2-[fluorine-18]Fluoroethyl)(methyl)amino]-2naphthyl $\}$-ethylidene)malononitrile (FDDNP) is the first PET tracer to visualise Alzheimer's disease pathology in living humans [16]. FDDNP is not an exclusive tau marker. In fact, it binds to both neurofibrillary tangles and amyloid plaques in the brains. In the first longitudinal PET study comparing the tracer binding of $\left[{ }^{11} \mathrm{C}\right] \mathrm{PIB}$ and $\left[{ }^{18} \mathrm{~F}\right] \mathrm{FDDNP}$ in $\mathrm{AD}$, mild cognitive impairment (MCI) patients and healthy controls, $\left[{ }^{18} \mathrm{~F}\right]$ FDDNP successfully discriminated between $\mathrm{AD}$ and healthy controls yet with a ninefold lower specific binding signal in comparison with $\left[{ }^{11} \mathrm{C}\right] \mathrm{PIB}$, which was thought to be due to both amyloid and tau [17]. Interestingly, the development of FDDNP opened the door for both amyloid and tau PET imaging in $\mathrm{AD}$, as well as other tauopathies. It was an important milestone since postmortem histopathological studies have consistently demonstrated that NFTs are better index of disease severity and progression, compared to $A \beta$. In addition, high clinical trial failure rate of disease-modifying drugs suggested that some of the basic assumptions of $\mathrm{AD}$ aetiology warrant reassessment and redirection [16].

Figure 2 demonstrates PET images of $\left[{ }^{18} \mathrm{~F}\right]$ FDDNP used in an $\mathrm{AD}$ patient.

\section{$\left[{ }^{11} \mathrm{C}\right] \mathrm{PBB} 3$}

Among the first generation of tau PET tracers, ${ }^{11} \mathrm{C}$-pyridinylbutadienyl-benzothiazole 3 ( $\left[{ }^{11} \mathrm{C}\right] \mathrm{PBB} 3$ ) was reported to detect a broad range of tau deposits. $\left[{ }^{11} \mathrm{C}\right] \mathrm{PBB} 3$, developed by
Higuchi and his colleagues, is a clinically used PET tracer allowed in vivo detection of tau inclusions in Alzheimer's disease as well as non-AD tauopathies in the human brain. While the signal of $\left[{ }^{11} \mathrm{C}\right]$ Pittsburgh compound $\mathrm{B}(\mathrm{PiB})$, one of the most commonly used PET tracer for detecting amyloid plaques, barely changed after the clinical onset of $\mathrm{AD}$, $\left[{ }^{11} \mathrm{C}\right] \mathrm{PBB} 3$ successfully demonstrated spreading of brain tau

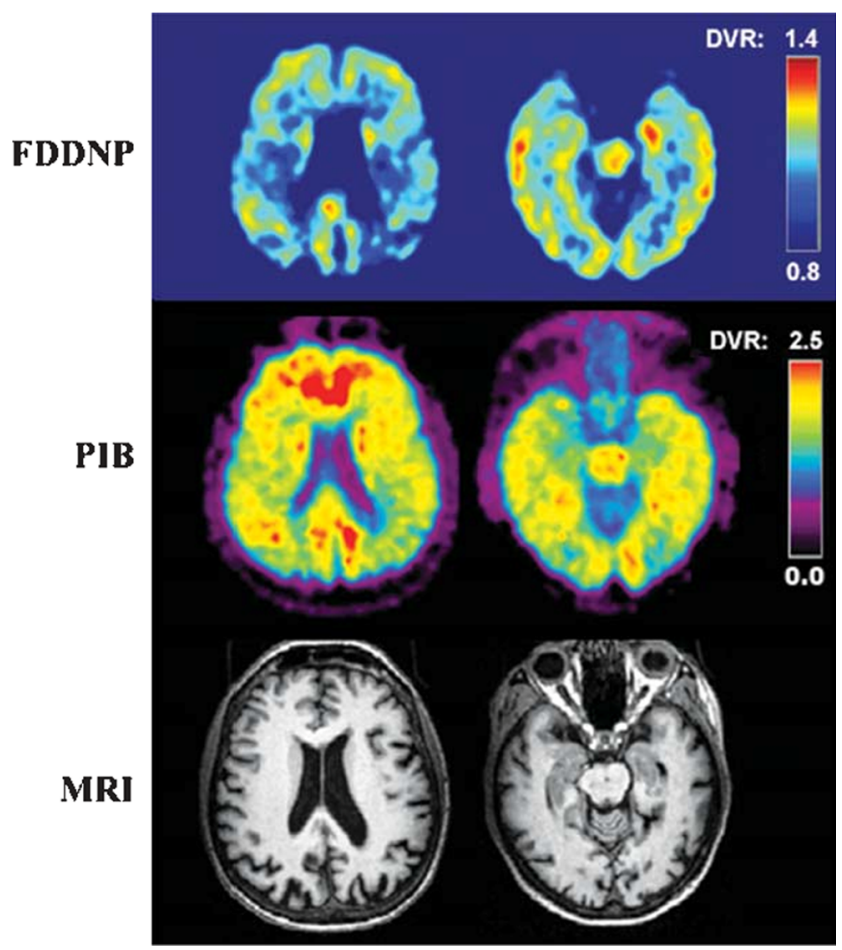

Fig. $2\left[{ }^{18}\right.$ F $]$ FDDNP-PET images. Co-registered FDDNP-PET, PIB-PET and MRI scans of a patient with Alzheimer's disease. Images in the left column: parietal lobe; images in the right column: temporal lobe. [16]. (Reprinted from J. Alzheimers Dis;26. Shin J, Kepe V, Barrio JR, Small GW. The merits of FDDNP-PET imaging in Alzheimer's disease., Suppl 3:135-145. Copyright (2011), with permission from IOS Press".) The publication is available at IOS Press through https://doi.org/10.3233/ JAD-2011-0008 
pathology in transition from normal ageing to moderate $\mathrm{AD}$, suggesting the usefulness of tau PET imaging as an objective index of disease progression [18]. This finding is in line with the notion that tau lesions are more tightly associated with neuronal dysfunction and disease progression than are $A \beta$ plaques.

In clinical PET human studies, $\left[{ }^{11} \mathrm{C}\right] \mathrm{PBB} 3$ clearly differentiated $\mathrm{AD}$ brains from healthy control brains and tracer retention in the hippocampus confirmed the binding ability to NFTs [12]. In $\mathrm{AD}$ patients, specific $\left[{ }^{11} \mathrm{C}\right] \mathrm{PBB} 3$ binding was observed in the $\mathrm{CA} 1$ and subiculum regions in the hippocampus, where high density of fibrillar tau aggregates exist [12]. High binding of $\left[{ }^{11} \mathrm{C}\right] \mathrm{PBB} 3$ was also detected in the medial temporal lobes, the precuneus and the frontal cortex. More importantly, the tracer retention was well correlated with cognitive decline and grey matter atrophy [19••]. Besides for its utility in Alzheimer's disease, in vivo PET data provided evidence that $\left[{ }^{11} \mathrm{C}\right] \mathrm{PBB} 3$ was capable of detecting tau aggregates in patients with non-AD dementias as exemplified by CBD as well [12]. Another study reported significant $\left[{ }^{11} \mathrm{C}\right] \mathrm{PBB} 3$ binding to tau deposits in the basal ganglia of a CBD case [20]. More studies of $\left[{ }^{11} \mathrm{C}\right] \mathrm{PBB} 3$ will validate the clinical usefulness of this tracer in various types of tauopathies. An example of $\left[{ }^{11} \mathrm{C}\right] \mathrm{PBB} 3$ images in AD patient is showed in Fig. 3.

\section{Quinoline Derivatives (THK Compounds)}

Novel quinoline derivatives were initially identified as candidates for tau PET tracer by the screening of over 2000 small molecules [22]. In vitro studies showed that three quinolone-derived tracers, $\left[{ }^{18} \mathrm{~F}\right]$ THK-523, $\left[{ }^{18} \mathrm{~F}\right]$ THK-5105 and $\left[{ }^{18} \mathrm{~F}\right]$ THK-5117, demonstrated selective and high binding affinity to tau over $\mathrm{A} \beta$ on $\mathrm{AD}$ brain sections [23-25]. However, $\left[{ }^{18} \mathrm{~F}\right] \mathrm{THK}-523$ failed to clearly visualise tau deposits in the human brain in vivo [26]. By contrast, $\left[{ }^{18} \mathrm{~F}\right]$ THK-5105 successfully demonstrated radiotracer retention in sites susceptible to tau deposition in the AD brain [27]. Recent PET studies demonstrated increased $\left[{ }^{18} \mathrm{~F}\right] \mathrm{THK} 5105$ and $\left[{ }^{18} \mathrm{~F}\right] \mathrm{THK} 5117$ tracer uptake in common sites of tau pathology in $\mathrm{AD}$ and its association with clinical severity of dementia $[27,28]$. It is important to mention that $\left[{ }^{18} \mathrm{~F}\right] \mathrm{THK}-5117 \mathrm{PET}$ showed higher signal-to-background ratio and better pharmacokinetics compared to $\left[{ }^{18} \mathrm{~F}\right] \mathrm{THK}-5105[21]$. Despite the exciting results showed by many studies, these THK compounds, like amyloid PET tracers, showed high nonspecific retention in the subcortical white matter. Signal from white matter binding could possibly obscure visual interpretation of PET images and decrease detection sensitivity for early tau pathology in the prodromal $\mathrm{AD}$.

To minimise nonspecific tracer retention in the white matter and increase the signal-to-background ratio of PET images, Harada and colleagues replaced a benzene ring of $\left[{ }^{18} \mathrm{~F}\right]$ THK5117 with pyridine and developed a novel tau PET tracer, $\left[{ }^{18} \mathrm{~F}\right]$ THK 5351. $\left[{ }^{18} \mathrm{~F}\right]$ THK5351 is a single S-enantiomer, which was expected to improve the pharmacokinetics of arylquinoline derivatives [15•*]. The group reported a higher binding affinity for hippocampal homogenates from $\mathrm{AD}$ brains and faster dissociation from white matter tissue of $\left[{ }^{18} \mathrm{~F}\right]$ THK5351 compared to $\left[{ }^{18} \mathrm{~F}\right] \mathrm{THK} 5117$. The level of tracer binding is still well correlated with the amount of tau deposits in human brain samples. More importantly, $\left[{ }^{18} \mathrm{~F}\right]$ THK5351 selectively bound to NFTs with a higher signal-to-background ratio than $\left[{ }^{18} \mathrm{~F}\right] \mathrm{THK} 5117$ did. First human PET studies showed that $\left[{ }^{18} \mathrm{~F}\right] \mathrm{THK} 5351$ has faster kinetics, higher contrast and lower retention in the subcortical white matter, suggesting that it is a useful PET tracer for the early detection of neurofibrillary pathology in AD patients $[15 \bullet \cdot]$. However, recent studies have demonstrated that monoamine oxidase inhibitor can reduce [18F]THK5351 uptake in the human brain.
Fig. $3\left[{ }^{11} \mathrm{C}\right] \mathrm{PBB} 3$ PET images. $\left[{ }^{11} \mathrm{C}\right] \mathrm{PBB} 3$ parametric standardised uptake value ratio (SUVR) images compared with $\left[{ }^{11} \mathrm{C}\right] \mathrm{PiB}$. $\left[{ }^{11} \mathrm{C}\right] \mathrm{PBB} 3$ shows tracer uptake in cortical areas in advanced $\mathrm{AD}$ patient. This research was originally published in JNM. Shah M, Catafau AM. Molecular Imaging Insights into Neurodegeneration: Focus on Tau PET Radiotracers. J. Nucl. Med. 2014;55:871-874. (C) SNMMI [21]

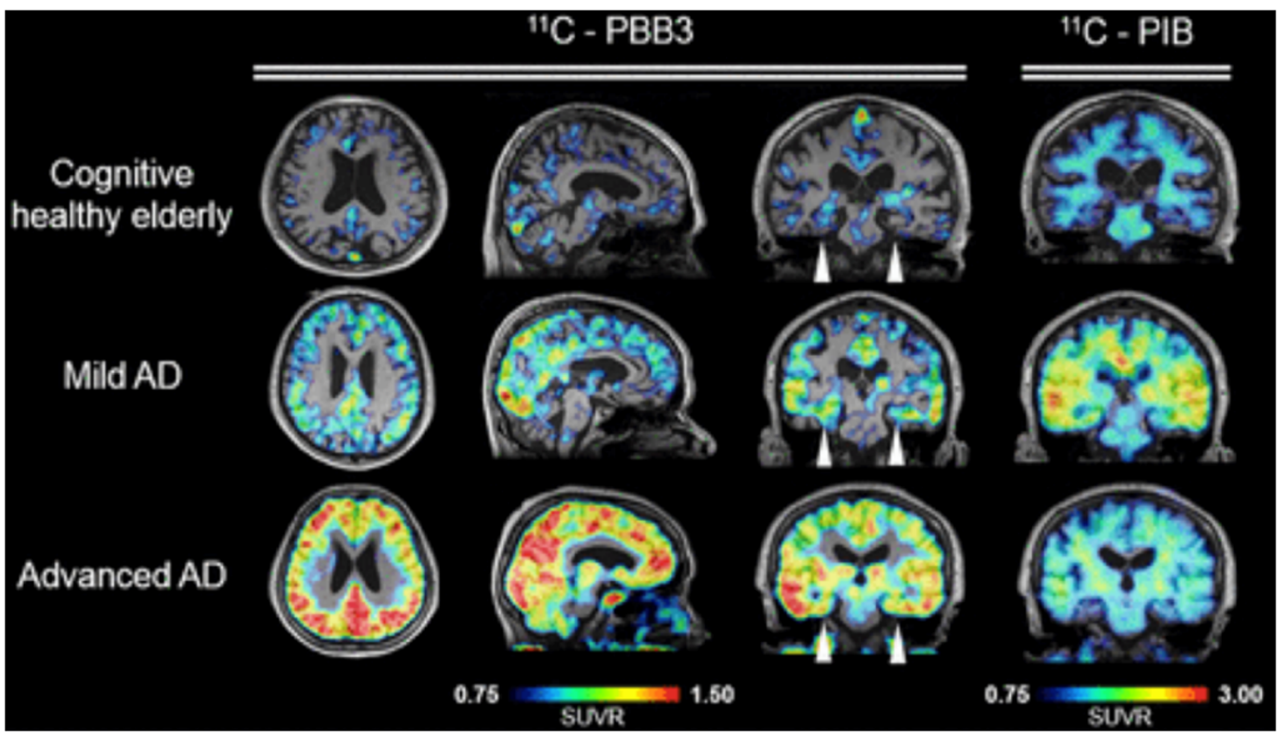


Figures of these THK compounds are illustrated in Fig. 4.

The first human PET study successfully demonstrated $\left[{ }^{18} \mathrm{~F}\right] \mathrm{AV}-1451$ retention in the frequent areas of PHF-tau in the AD brain [13]. In addition, the tracer retention was associated with increased disease severity, supported by the highly elevated and extensive $\left[{ }^{18} \mathrm{~F}\right] \mathrm{AV}-1451$ retention in severe $\mathrm{AD}$ case than in MCI and mild AD cases. Unlike most ${ }^{18} \mathrm{~F}$-labelled amyloid PET tracers, $\left[{ }^{18} \mathrm{~F}\right] \mathrm{AV}-1451$ showed very low nonspecific binding to the white matter, which may improve the grey-to-white matter contrast in the brain. However, it is worth noticing that AV1451 showed substantial variability in healthy controls, especially subjects younger than 40. Suzanne Baker and colleagues found that non-specific binding of $\left[{ }^{18} \mathrm{~F}\right]$ AV1451 in the brain reflects both age-related (putamen) and non-age-related pattern (white matter/thalamus). The results suggested that these factors may reduce signal to noise at low levels of tracer binding [31••]. Interestingly, an in vivo study reported that $\left[{ }^{18} \mathrm{~F}\right] \mathrm{AV}-1451$ showed higher level of binding in microtubule-associated protein tau $(M A P T)$ mutation carriers who harbour mutations that are more likely to produce AD-like tau pathology. This finding further supported the notion that $\left[{ }^{18} \mathrm{~F}\right] \mathrm{AV}-1451$ has specific binding properties for $\mathrm{AD}$ like tau pathology. Most excitingly, $\left[{ }^{18} \mathrm{~F}\right] \mathrm{AV}-1451$ has just been announced to meet its two primary endpoints, defined as predicting brain tau pathology and predicting Alzheimer's disease diagnosis, in a phase III study (A16 trial). Primary outcomes showed a pattern of tracer uptake that corresponded to NFT accumulation consistent with Braak stage V/VI, and a pattern consistent with high levels of AD neuropathologic change as defined by National Institute on AgingAlzheimer's Association (NIA-AA) criteria. However, the data would not be able to prove the reliability of $\left[{ }^{18} \mathrm{~F}\right] \mathrm{AV}-1451$ in

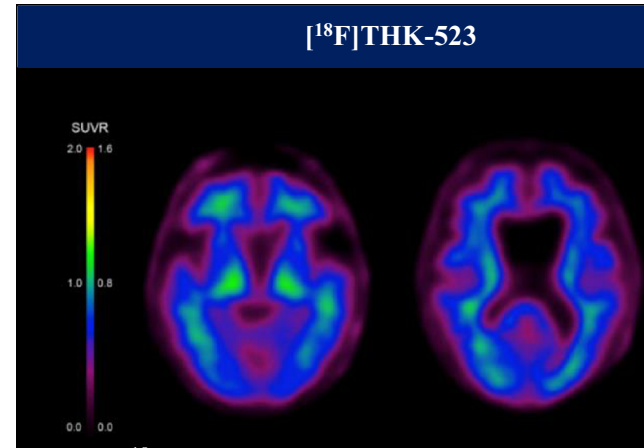

$\left[{ }^{18} \mathrm{~F}\right]$ THK523 PET images from a progressive supranuclear palsy patient. This research was originally published in Alzheimers Res. Ther [29].

$\left[{ }^{18}\right.$ F]THK-5117 Eur. J. Nucl. Med. Mol. Imaging [28] Copyright (2015).

\section{$\left[{ }^{18} \mathrm{~F}\right]$ THK-5105}

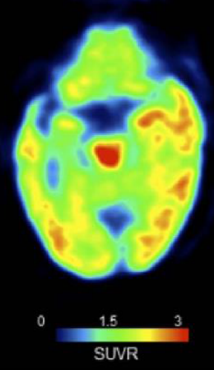

$\left[{ }^{18} \mathrm{~F}\right]$ THK5105 PET images from a patient with dementia resulting from AD. [Images courtesy of Prof. Nobuyuki Okamura, Tohoku University]

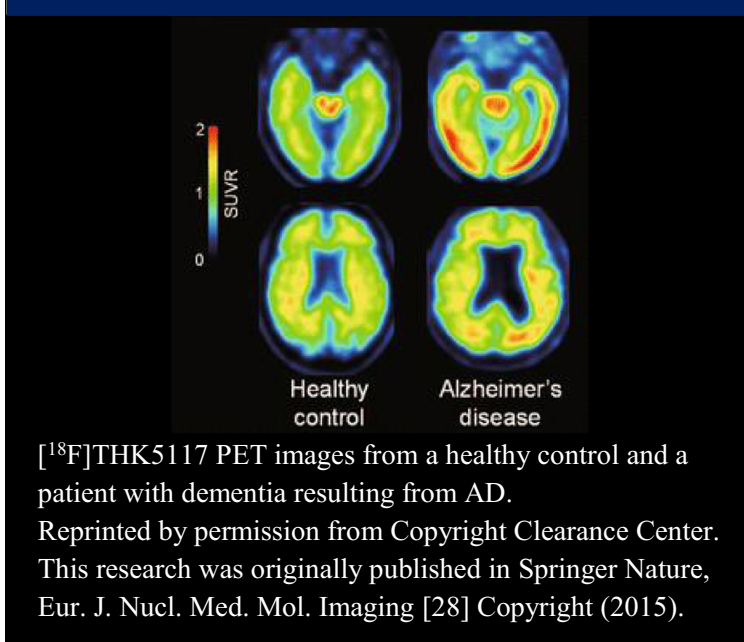

$\left[{ }^{18} \mathrm{~F}\right]$ THK5117 PET images from a healthy control and a patient with dementia resulting from AD

Reprinted by permission from Copyright Clearance Center. This research was originally published in Springer Nature,

Fig. 4 PET images of THK compounds. $\left[{ }^{18} \mathrm{~F}\right] \mathrm{AV}-1451$ (T807). $\left[{ }^{18} \mathrm{~F}\right] \mathrm{AV}-$ 1451 (flortaucipir, T807) exhibited strong and selective binding affinity to PHF-tau on AD brain [13, 30]. With favourable pharmacokinetics and a binding pattern consistent with the Braak staging, $\left[{ }^{18} \mathrm{~F}\right] \mathrm{AV}-1451$ is considered as the most promising PET candidates for tau imaging [21]. Clinical $\left[{ }^{18} \mathrm{~F}\right] \mathrm{AV}-1451$ PET scans are demonstrated in Fig. 5. (THK-523

\section{$\left[{ }^{18} \mathrm{~F} \mid \mathrm{THK}-5351\right.$}

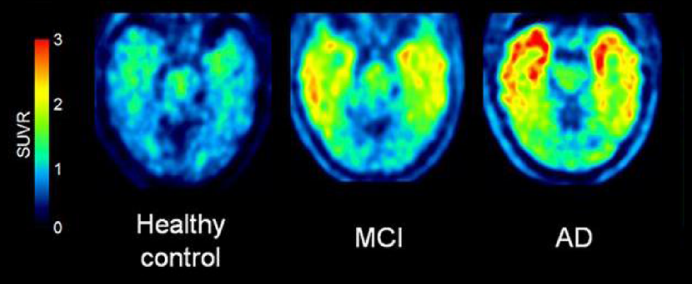

$\left[{ }^{18} \mathrm{~F}\right]$ THK5351 PET images shows low uptake in healthy controls, intermediate uptake in MCI patient, and intense tau pathology spreading across the frontal and temporal cortex in Alzheimer's disease. [Image courtesy of Prof. Nobuyuki Okamura, Tohoku University.]

This research was originally published in Alzheimers Res. Ther) [29] (THK-5105 and THK-5351 Images courtesy of Prof. Nobuyuki Okamura, Tohoku University) (THK-5117 Reprinted by permission from Copyright Clearance Center. This research was originally published in Springer Nature, Eur. J. Nucl. Med. Mol. Imaging [28] Copyright (2015) 
people at earlier Braak stages for example stages III and IV, which are clinically meaningful. Further research is needed for the validation of the tracer.

In a recent study aiming for modelling amyloid, tau and cortical thickness changes across the Alzheimer's disease spectrum, Jungho Cha et al. found that AV1451 appeared to increase after $\mathrm{PiB}$ reached a plateau, but preceded changes in cortical thickness [32]. These results were consistent with the notion that $\mathrm{AD}$ is an amyloid-facilitated tauopathy and in turn leads to atrophy of neurons. In another study examining effects of APOE $\varepsilon 4$ on tau pathology in $\mathrm{AD}$, Niklas Mattsson and colleagues found that APOE $\varepsilon 4$-negative AD patients showed significantly greater tau load and reduced cortical thickness specifically in the parietal cortex compared to their APOE \&4-positive counterparts [33]. A longitudinal tau PET study running in ageing and $\mathrm{AD}$ subjects by Clifford Jack et al. showed that the rate measurements based on Braak topographic staging of NFTs or voxel-wise approaches may not necessarily provide substantially more information than simple meta-ROI rate measurements. They further suggested that tau PET standardised uptake value ratio (SUVRs) measures would be an efficient outcome measurement in diseasemodifying clinical trials [34.0]. Another recent study by Tharick Pascoal et al. examined the voxel-wise sensitivity, specificity, area under the curve (AUC) and thresholds of neurofibrillary tangle deposition in AD using $\left[{ }^{18} \mathrm{~F}\right] \mathrm{AV} 1451$ and $\left[{ }^{18} \mathrm{~F}\right] \mathrm{MK} 6240$. Their findings indicated that the regional thresholds of tau PET ligands have the potential to be used in clinical trials for the enrolment of individuals with tau abnormalities [35]. It is very important to note that although tau has been indicated to strongly associate with cognition, considerable overlap of tau PET measurements across cognitively normal and AD subjects has been observed. Susan Landau and colleagues found that AV1451 SUVRs of one third to one half of amyloid-positive $\mathrm{MCI}$ and $\mathrm{AD}$ patients overlapped with amyloid-negative healthy controls. This finding poses a challenge for using tau as a biomarker for cognitive impairment.

$\left[{ }^{18} \mathrm{~F}\right] \mathrm{T} 808$ showed a high level of binding affinity and good selectivity for tau aggregates over amyloid $\beta$ plaques in in vitro assays as well as rapid uptake and washout in rodent brains. Further preclinical in vivo studies suggested that $\left[{ }^{18} \mathrm{~F}\right] \mathrm{T} 808$ possesses suitable properties and characteristics to be a specific and selective PET probe for imaging of paired helical filament tau in human brains [36]. More rapid tracer distribution throughout the brain and more rapid clearance from normal brain tissue of $\left[{ }^{18} \mathrm{~F}\right] \mathrm{T} 808$ compared to $\left[{ }^{18} \mathrm{~F}\right] \mathrm{AV}$ 1451 were observed in human clinical studies [14]. However, substantial defluorination has been observed with $\left[{ }^{18} \mathrm{~F}\right] \mathrm{T} 808$, and thus it is not taken forward [11].

\section{Current Challenges in Developing Tau Tracers}

The development of tau imaging radioligands has enabled visualisation of tau depositions in tauopathy patients, but the modes of their binding to different tau strains still remains unclear. In the development of PET radioligand for tau imaging, several aspects have made it challenging.

First, the candidate PET ligands were designed to target $\beta$ pleated sheets, a protein structural motif that is shared by both tau and $A \beta$, thereby raising the possibility of cross-reaction [18]. The fact that tau aggregates are coexistent with $A \beta$ plaques with 5 to 20 times lower concentrations than $A \beta$ plaques made it even more difficult to develop a highly selective tau PET imaging tracers [11]. Secondly, the complexity of developing a radioligand targeting tau protein is increased because of its intracellular location [37••], which means the ligands need to be able to pass through the plasma membrane as well as the blood-brain barrier in order to reach tau protein [18]. Another critical challenge is primarily due to the nature of tau protein in human brains. Through alternative splicing of the MAPT gene, six isoforms of tau are expressed in the adult human central nervous system, giving rise to two sets of isoforms: 3R-tau and 4R-tau. Diverse neurodegenerative disorders are characterised by deposition of tau fibrils composed of conformers (i.e., strains) unique to each illness. Under pathological circumstances, several tauopathies express different isoform ratios with diverse morphologies. These structural differences lead to the difficulty of developing a tau-specific tracer, with similar affinity for every phenotype [38]. Furthermore, tau is subjected to many posttranslational modifications, which may result in conformational changes in the aggregates, potentially leading to different binding affinities of tau ligands [39]. Last is the "off-target" binding of the tracers. It has become clear that these tracers detected the distribution of not only tau but also other proteins in the brain, which might possibly due to the structural motifs [40]. For example, both $\left[{ }^{18} \mathrm{~F}\right] \mathrm{AV}-1451$ and $\left[{ }^{18} \mathrm{~F}\right] \mathrm{THK} 5351$ have been found to also bind to monoamine oxidases (MAO) $[41 \cdot, 42]$. Moreover, $\left[{ }^{18} \mathrm{~F}\right] \mathrm{AV}-1451$ is well known to bind to calcifications, iron, melanin and blood vessels [43].

\section{Comparison of First-Generation Tau Tracers}

Diverse neurodegenerative disorders are characterised by the abnormal accumulation of tau fibrils composed of different strains unique to each illness. Several PET tracers have been developed for visualisation of tau deposition under heterogeneous tau pathology, but the modes of their binding to different tau strains remain unclear $[44 \bullet, 45 \bullet \cdot$. Head-to-head comparison of different tau tracers is commonly used for researchers to evaluate the pharmacokinetics of different tracers in terms of their uptake, distribution, clearance and metabolism. This provides crucial information for the selection of PET imaging ligands capable of binding to one or more tau fibril strains in different tauopathies.

One in vivo study evaluated the binding of $\left[{ }^{11} \mathrm{C}\right]$ THK5351 and $\left[{ }^{11} \mathrm{C}\right] \mathrm{PBB} 3$ in a head-to-head multimodal design. The 


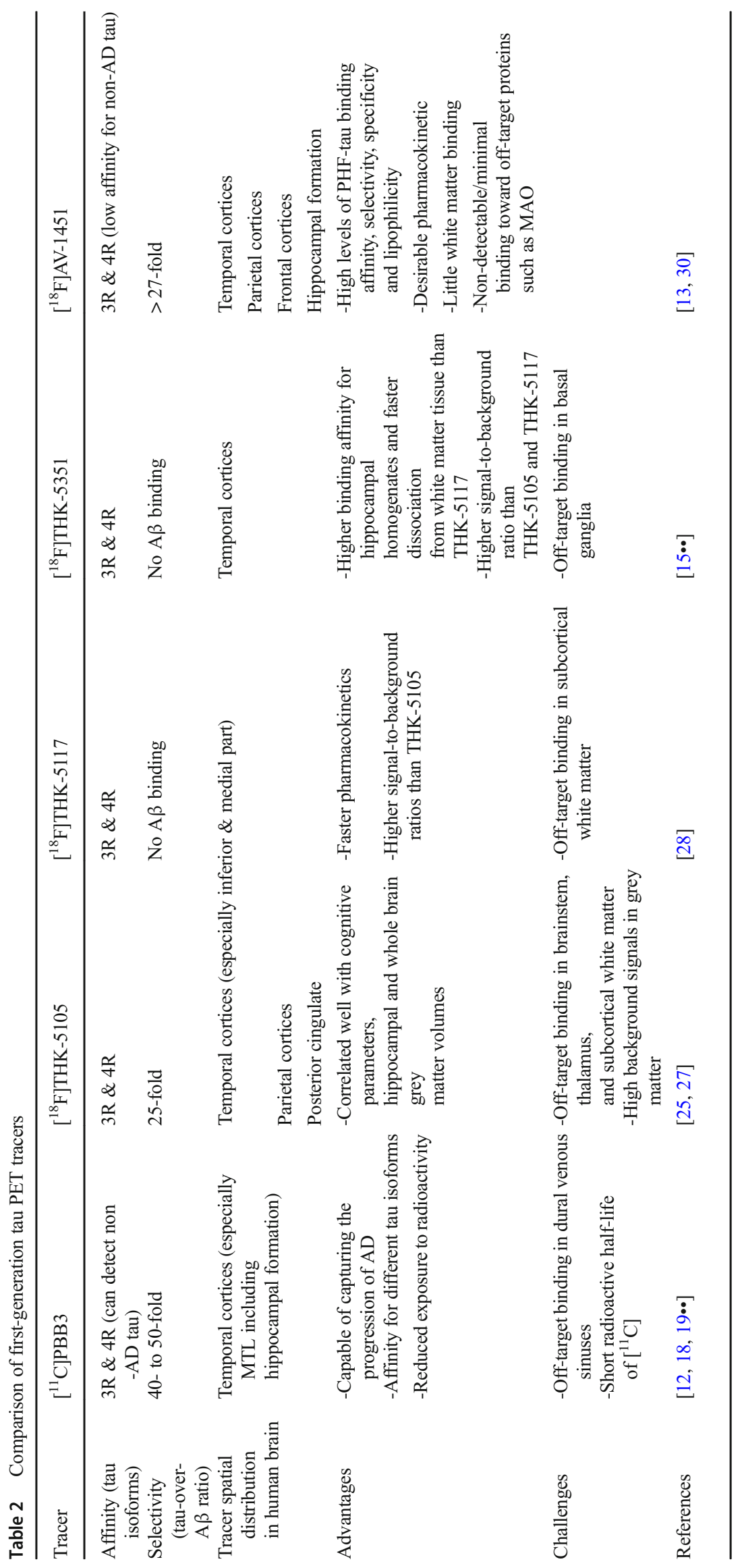


findings indicated different molecular targets for these tracers. While $\left[{ }^{11} \mathrm{C}\right] \mathrm{PBB} 3$ appeared to preferentially bind to tau deposits with a close spatial relationship to $A \beta$, the binding pattern of $\left[{ }^{11} \mathrm{C}\right]$ THK5351 fitted the expected distribution of tau pathology in Alzheimer's disease better and was more closely related to downstream disease markers [46]. $\left[{ }^{11} \mathrm{C}\right] \mathrm{PBB} 3$ and $\left[{ }^{18} \mathrm{~F}\right] \mathrm{AV}-1451$ were also compared in an in vitro study. Results indicated distinct selectivity of $\left[{ }^{11} \mathrm{C}\right] \mathrm{PBB} 3$ compared to $\left[{ }^{18} \mathrm{~F}\right] \mathrm{AV}-1451$ for diverse tau fibril strains. This highlighted the more robust ability of $\left[{ }^{11} \mathrm{C}\right] \mathrm{PBB} 3$ to capture wide-range tau pathologies [47•]. In a preclinical study using mouse model of tau pathology, tracer uptake in the brainstem of $\left[{ }^{18} \mathrm{~F}\right] \mathrm{AV}-1451$ showed to be moderately superior to $\left[{ }^{18} \mathrm{~F}\right]$ THK5 5117 regarding sensitivity for preclinical tau imaging. Another study compared $\left[{ }^{18} \mathrm{~F}\right] \mathrm{AV}-1451$ and $\left[{ }^{18} \mathrm{~F}\right]$ THK5351 in Alzheimer's disease and frontotemporal dementia cases. Although AV-1451 and THK5351 uptakes were highly correlated, cortical uptake of AV-1451 was more striking in Alzheimer's disease, while cortical uptake of THK5351 was more prominent in frontotemporal dementia. THK 5351 showed higher off-target binding than AV-1451 in the white matter, midbrain, thalamus and basal ganglia. The results indicated that AV-1451 is more sensitive and specific to
Alzheimer's disease type tau, while THK5351 may mirror general non-specific neurodegeneration [48].

A brief summary of first-generation tau tracers is listed in Table 2. Some recent clinical study using different firstgeneration tau tracers are summarised in Table 3.

\section{Second-Generation Tau Tracers}

Imaging agents capable of quantifying the brain's tau aggregates allow a more precise staging of Alzheimer's disease. Since first-generation tau PET ligands bind predominantly to AD-typical 3R-/4R-tau isoforms and exhibit off-target binding as well as subcortical white matter uptake, several research institutes and pharmaceutical companies have been trying to improve the binding selectivity and pharmacokinetics of tau PET tracers. These second-generation tau PET ligands appear to bind to comparable binding sites but showed less brain offtarget binding. Chemical structures of first- and secondgeneration tau PET tracers are illustrated in Table $4 .{ }^{18} \mathrm{~F}$-labelled PBB derivatives, APN-1607 ([ $\left.\left.{ }^{18} \mathrm{~F}\right] \mathrm{PM}-\mathrm{PBB} 3\right)$ showed a greater signal-to-background ratio and less off-target signals in the basal ganglia than $\left[{ }^{11} \mathrm{C}\right] \mathrm{PBB} 3 .\left[{ }^{18} \mathrm{~F}\right] \mathrm{GTP} 1$, another second-generation tau tracer, was showed to correlate with

Table 3 Highlight of recent clinical human PET study

\begin{tabular}{|c|c|c|}
\hline Subjects & Major findings & References \\
\hline 9 MCI patients (prodromal AD) & $\begin{array}{l}-\left[{ }^{11} \mathrm{C}\right] \mathrm{PBB} 3 \text { preferentially bind to tau deposits with a close spatial relationship to } \mathrm{A} \beta \\
-\left[{ }^{11} \mathrm{C}\right] \mathrm{THK} 5351 \text { presented the distribution of tau pathology in } \mathrm{AD} \text { better and was } \\
\text { more closely related to downstream disease markers }\end{array}$ & [46] \\
\hline $3 \mathrm{AD}$ patients and $3 \mathrm{HCs}$ & $\begin{array}{l}{\left[{ }^{11} \mathrm{C}\right] \mathrm{PBB} 3 \text { tracer distribution was consistent with the spreading of tau pathology }} \\
\text { with } \mathrm{AD} \text { progression }\end{array}$ & {$[12]$} \\
\hline $\begin{array}{l}2 \text { AD patients, } 4 \text { FTD patients (frontotemporal } \\
\text { dementia) and } 2 \text { HCs }\end{array}$ & $\begin{array}{l}-\left[{ }^{18} \mathrm{~F}\right] \mathrm{AV}-1451 \text { is more sensitive and specific to Alzheimer's disease type tau and } \\
\text { shows lower off-target binding } \\
{\left[{ }^{18} \mathrm{~F}\right] \text { THK5351 may better present non-specific neurodegeneration }}\end{array}$ & [48] \\
\hline 69 healthy controls (PIB negative) & Explained $\left[{ }^{18} \mathrm{~F}\right] \mathrm{AV}-1451$ variability in healthy controls across the lifespan. & {$[31]$} \\
\hline $\begin{array}{l}6 \text { AD patients, } 3 \text { PSP patients, } 2 \text { CBS patients and } 4 \\
\text { HCs }\end{array}$ & $\begin{array}{l}\text { Described the kinetics of }\left[{ }^{18} \mathrm{~F}\right] \mathrm{AV}-1451 \text {, the optimal scanning time and the reference } \\
\text { region for SUVR calculation. }\end{array}$ & [49] \\
\hline 3 subjects carrying the $M A P T$ R $406 \mathrm{~W}$ mutation & $\begin{array}{l}{\left[{ }^{18} \mathrm{~F}\right] \mathrm{AV}-1451 \text { PET can be used to accurately quantify in vivo the regional }} \\
\text { distribution of hyperphosphorylated tau protein. }\end{array}$ & {$[50]$} \\
\hline $\begin{array}{l}20 \text { EOAD patients, } 21 \text { LOAD patients, } 3 \text { prodromal } \\
\text { EOAD } 13 \text { prodromal LOAD and } 30 \mathrm{HCs}\end{array}$ & $\begin{array}{l}\text { Described the difference in }\left[{ }^{18} \mathrm{~F}\right] \mathrm{AV}-1451 \text { tracer retention in early- and late-onset } \\
\text { Alzheimer's disease. }\end{array}$ & [51] \\
\hline $39 \mathrm{AD}$ patients, 14 prodromal $\mathrm{AD}$ and $30 \mathrm{HCs}$ & $\begin{array}{l}\text { Elucidated the relationship of }\left[{ }^{18} \mathrm{~F}\right] \mathrm{AV}-1451 \text { tracer retention to tau in cerebrospinal } \\
\text { fluid. }\end{array}$ & {$[52 \cdot]$} \\
\hline $11 \mathrm{PSP}$ patients and $11 \mathrm{HCs}$ & Characterised the tracer uptake of $\left[{ }^{18} \mathrm{~F}\right] \mathrm{AV}-1451$ in progressive supranuclear palsy. & {$[53 \bullet]$} \\
\hline One 71-year-old male subject & & {$[54]$} \\
\hline $\begin{array}{l}31 \text { AD patients, } 11 \text { PSP patients, } 8 \text { CBS patients and } \\
17 \mathrm{HCs}\end{array}$ & Characterised the tracer uptake of $\left[{ }^{18} \mathrm{~F}\right] \mathrm{AV}-1451$ in corticobasal syndrome. & {$\left[55^{\bullet}\right]$} \\
\hline $17 \mathrm{AD}$ patients and $95 \mathrm{HCs}$ & $\begin{array}{l}\text { Regional thresholds of }\left[{ }^{18} \mathrm{~F}\right] \mathrm{AV}-1451 \text { have the potential to be used in clinical trials } \\
\text { for the enrolment of individuals with tau abnormalities. }\end{array}$ & {$[35]$} \\
\hline $\begin{array}{l}59 \text { cognitively unimpaired with normal amyloid } \\
\text { (CUA-) } \\
37 \text { cognitively unimpaired with abnormal amyloid } \\
\text { (CUA+) }\end{array}$ & $\begin{array}{l}\text {-Rate measurements based on granular Braak-like topographic staging or } \\
\text { voxel-wise approaches may not provide significantly more information than } \\
\text { simple meta-ROI rate measurements. }\end{array}$ & {$[34 \bullet \bullet]$} \\
\hline $\begin{array}{l}30 \text { cognitively impaired with amnestic phenotype } \\
\text { and abnormal amyloid (CIA+) }\end{array}$ & $\begin{array}{l}\text {-Tau PET SUVR measures should be an efficient outcome measure in } \\
\text { disease-modifying clinical trials. }\end{array}$ & \\
\hline
\end{tabular}


Table 4 Chemical structures of first and second generation of tau PET tracers

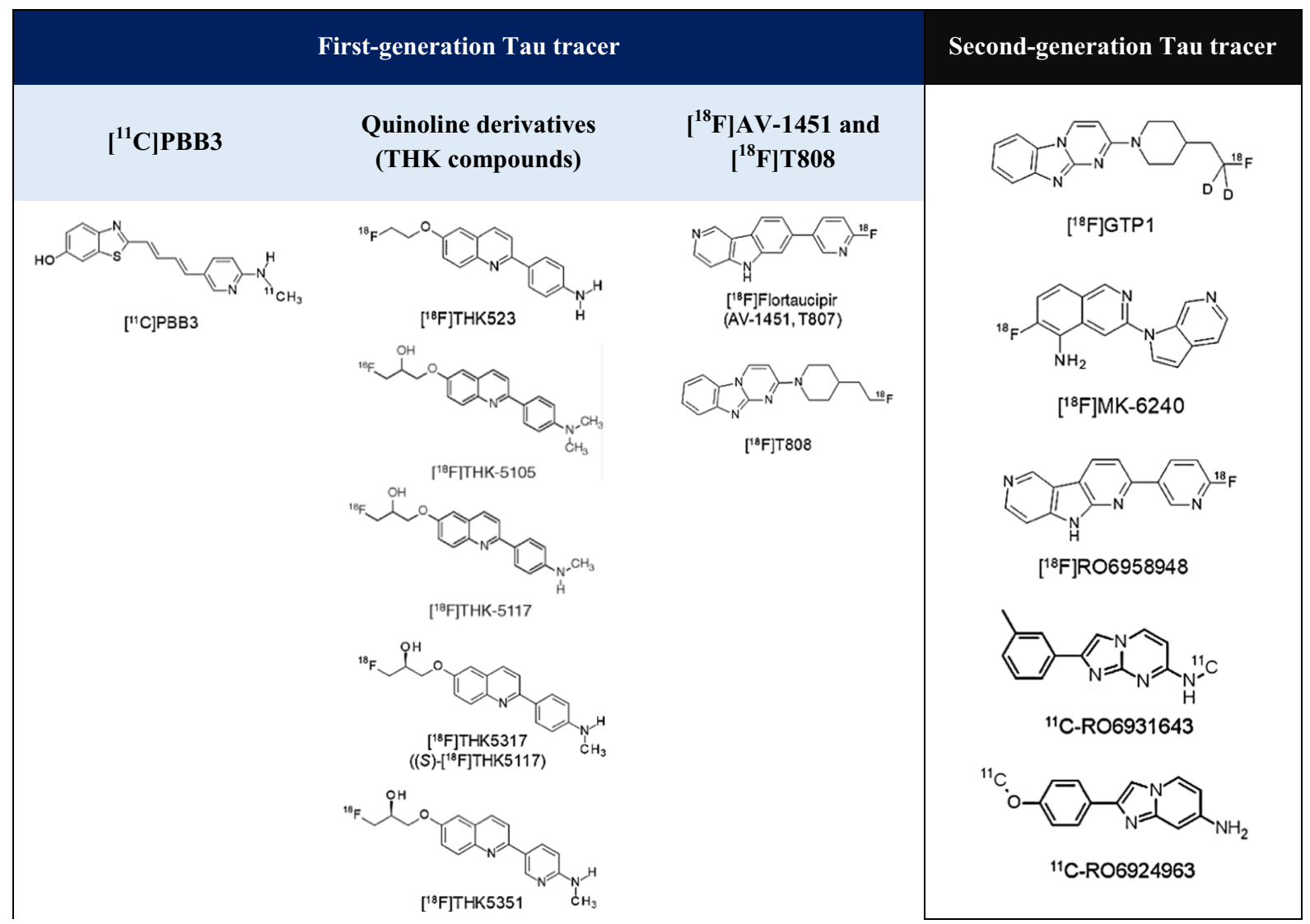

AD pathology. A clinical PET study of $\left[{ }^{18} \mathrm{~F}\right] \mathrm{GTP} 1$ successfully prevented tracer accumulation in the skull and clearly differentiated $\mathrm{AD}$ patients from healthy control subjects [56].

$\left[{ }^{18} \mathrm{~F}\right] \mathrm{MK}-6240$, a novel pyridine isoquinoline amine derivative, showed high sensitivity and specificity for PHF-tau binding [57] and displayed favourable kinetics with rapid brain delivery and washout. In AD patients, $\left[{ }^{18} \mathrm{~F}\right] \mathrm{MK}-6240$ uptake was higher in brain regions expected to contain NFTs such as the hippocampus, whereas no difference was found in the cerebellar grey matter. It is worth noticing that the
Fig. $5\left[{ }^{18} \mathrm{~F}\right] \mathrm{AV}-1451$ PET images. $\left[{ }^{18} \mathrm{~F}\right] \mathrm{AV}-1451$ showed an increased parieto-temporal uptake in an $\mathrm{AD}$ subject. Other figures presented the tracer retention in CBD, PSP and a cognitively healthy elderly subject. [Image courtesy of Prof. Oskar Hansson, The Swedish BIOFINDER Study. http://biofinder.se]

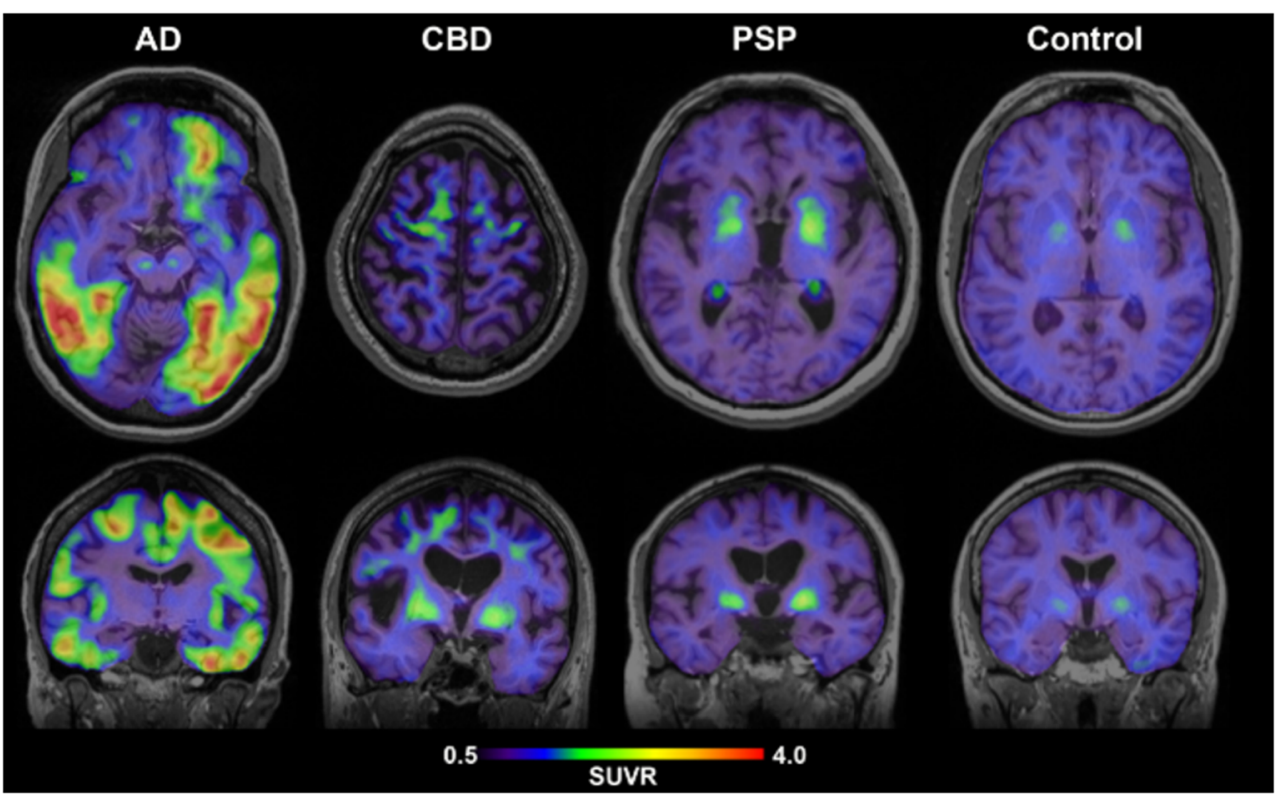




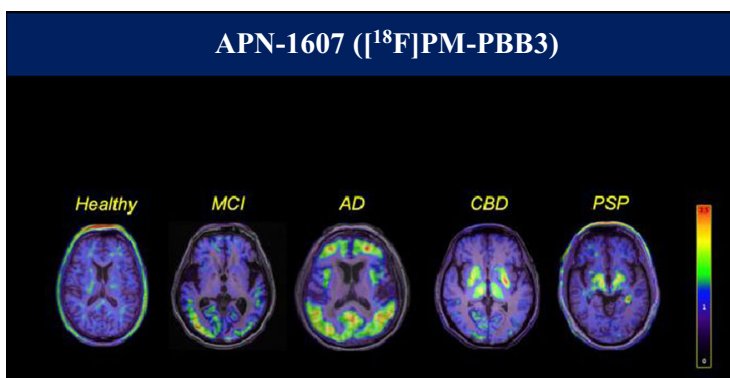

Clinical PET images with APN-1607 developed by APRINOIA Therapeutics in MCI, AD, CBD and PSP patients. [Image courtesy of Kunju Lin, Chang Gung Memorial Hospital and Ming-Kuei Jang, APRINOIA Therapeutics.]

$\left.{ }^{18} \mathrm{~F}\right] \mathrm{MK}-6240$
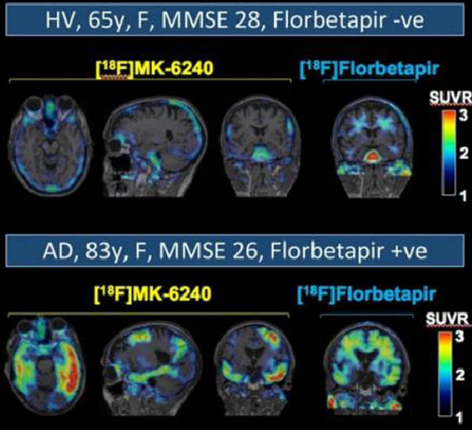

SUVR $_{60-90}$ with cerebellar cortex reference

Clinical PET images with $\left[{ }^{18} \mathrm{~F}\right] \mathrm{MK}-6240$ in healthy control (up) and $\mathrm{AD}$ patient (down). AD patient showed high MK6240 uptake in known tau pathology regions such as the medial temporal lobe and inferior temporal cortex. [Image courtesy of Cyrille Sur, Merck.]

\section{$\left[{ }^{18}\right.$ F $]$ GTP1}

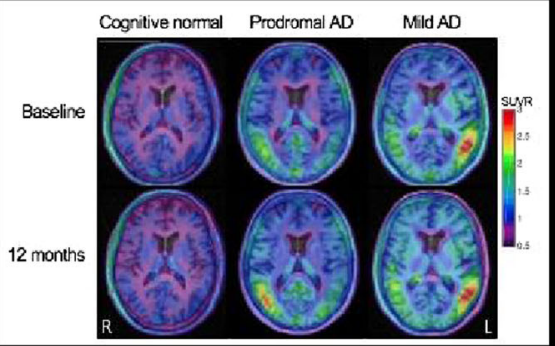

Genentech's GTP1 tracer reveals an increase in tau accumulation in prodromal and mild $\mathrm{AD}$ patient over 12 months. [Image courtesy of Sandra Sanabria Bohorquez, Genentech.]

\section{$\left[{ }^{18} \mathrm{~F}\right] \mathrm{PI}-2620$}

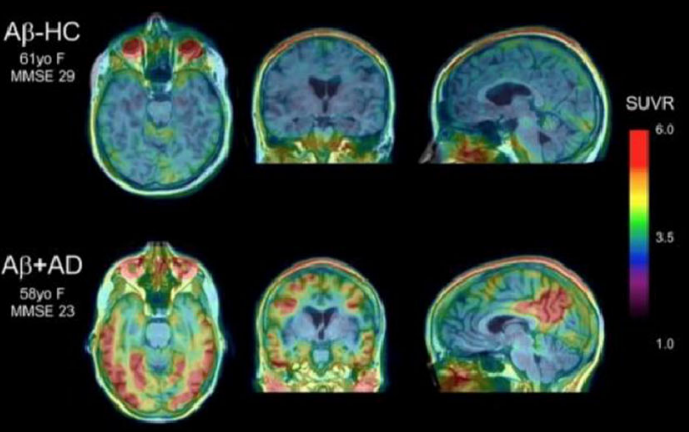

PI-2620 tracer performance in a healthy control (top) and AD patient (down). [Reproduced from Leuzy, Antoine et al., Molecular Psychiatry, January 2019;

https://www.nature.com/articles/s41380-0180342-8; Creative Commons user license

\section{$\left.{ }^{18} \mathrm{~F}\right] \mathrm{RO}-948$}

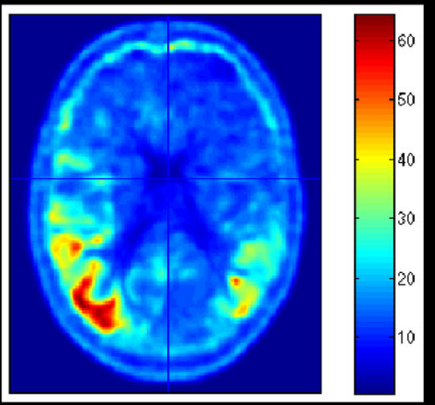

SUVR image of an AD case using the R0948-tracer (64 yrs, female, MMSE 19; A-beta, pTau and tTau positive in CSF). [Image courtesy of Prof. Oskar Hansson.] 
Fig. 6 PET images of second-generation Tau tracers. (APN-1607 Image courtesy of Kunju Lin, Chang Gung Memorial Hospital and Ming-Kuei Jang, APRINOIA Therapeutics.) (GTP1 Image courtesy of Sandra Sanabria Bohorquez, Genentech) (MK-6240 Image courtesy of Cyrille Sur, Merck.) (PI-2620 Reproduced from Leuzy, Antoine et al., Molecular Psychiatry, January 2019; https://www.nature.com/articles/s41380-018-0342-8; Creative Commons user licence http://creativecommons.org/licenses/by/4.0/) (RO-948 Image courtesy of Prof. Oskar Hansson)

cerebellar grey matter showed very low binding across individuals, suggesting the potential for use as a reference region. Reliability analysis revealed robust SUVRs, indicating that simplified quantitative approaches could offer valid estimates of NFTs load [58]. Absence of off-target binding of MK-6240 to MAO-A and MAO-B was confirmed in preclinical studies as well [59]. Recent clinical studies have demonstrated that spatial patterns of MK-6240 binding were consistent with neuropathological staging of NFTs [60]. Unlike $\left[{ }^{18} \mathrm{~F}\right] \mathrm{T} 807$ and $\left[{ }^{18} \mathrm{~F}\right] \mathrm{THK} 5351$, off-target binding of MK-6240 was not observed in the basal ganglia and choroid plexus $[60] .\left[{ }^{18} \mathrm{~F}\right] \mathrm{MK}-6240$ is a promising tau tracer with the potential to be applied in the disease diagnosis and assessment of therapeutic interventions. To confirm these initial observations, several clinical studies are ongoing in nonAD patients [61]. Another novel tracer $\left[{ }^{18} \mathrm{~F}\right] \mathrm{PI}-2620$ has also shown a lack of off-target binding in the choroid plexus, basal ganglia, striatum, amygdala, meninges or other regions noted in first-generation tau agents [62]. In their study, both $\mathrm{AD}$ and PSP patients demonstrated evident tracer uptake compared to non-demented controls. Initial pharmacokinetic modelling indicated that SUVr from 60 to 90 min could be a good proxy for DVR, although awaiting validation.

$\left[{ }^{18} \mathrm{~F}\right] \mathrm{RO} 6958948$ (RO-948), $\left[{ }^{11} \mathrm{C}\right] \mathrm{RO} 6931643$ (RO-643) and $\left[{ }^{11} \mathrm{C}\right] \mathrm{RO} 6924963$ (RO-963) were identified as highaffinity competitors at the ${ }^{3} \mathrm{H}$-T808 binding site on native tau aggregates in human late-stage $\mathrm{AD}$ brain tissue [63]. By macro- and micro-autoradiography and by co-staining of tau aggregates and $A \beta$ plaques on the same tissue section using specific antibodies, the research group was able to assess the uptake, distribution, clearance and metabolism of these three tracers. $\left[{ }^{18} \mathrm{~F}\right] \mathrm{RO} 6958948,\left[{ }^{11} \mathrm{C}\right] \mathrm{RO} 6931643$ and $\left[{ }^{11} \mathrm{C}\right] \mathrm{RO6924963}$ all showed good brain entry, rapid washout, high affinity for NFTs and excellent selectivity against $\mathrm{A} \beta$ plaques in AD brain tissues. Among them, $\left[{ }^{18} \mathrm{~F}\right] \mathrm{RO} 6958948$ showed appropriate pharmacokinetic and metabolic properties in mice and non-human primates [63, 64]. Preclinical binding analysis has also proved lower binding affinity of these compounds to MAO-A and MAO-B than the binding affinity of $\left[{ }^{18} \mathrm{~F}\right] \mathrm{THK} 5351$ and $\left[{ }^{18} \mathrm{~F}\right] \mathrm{T} 807$. Importantly, the results from a first-in-human PET study were consistent with preclinical data [65•]. In addition, $\left[{ }^{18} \mathrm{~F}\right] \mathrm{RO} 6958948$ showed a better signal-tobackground ratio than $\left[{ }^{11} \mathrm{C}\right] \mathrm{RO} 6931643$ and $\left[{ }^{11} \mathrm{C}\right] \mathrm{RO} 6924963$ in AD patients [56] (Fig. 5). Clinical PET

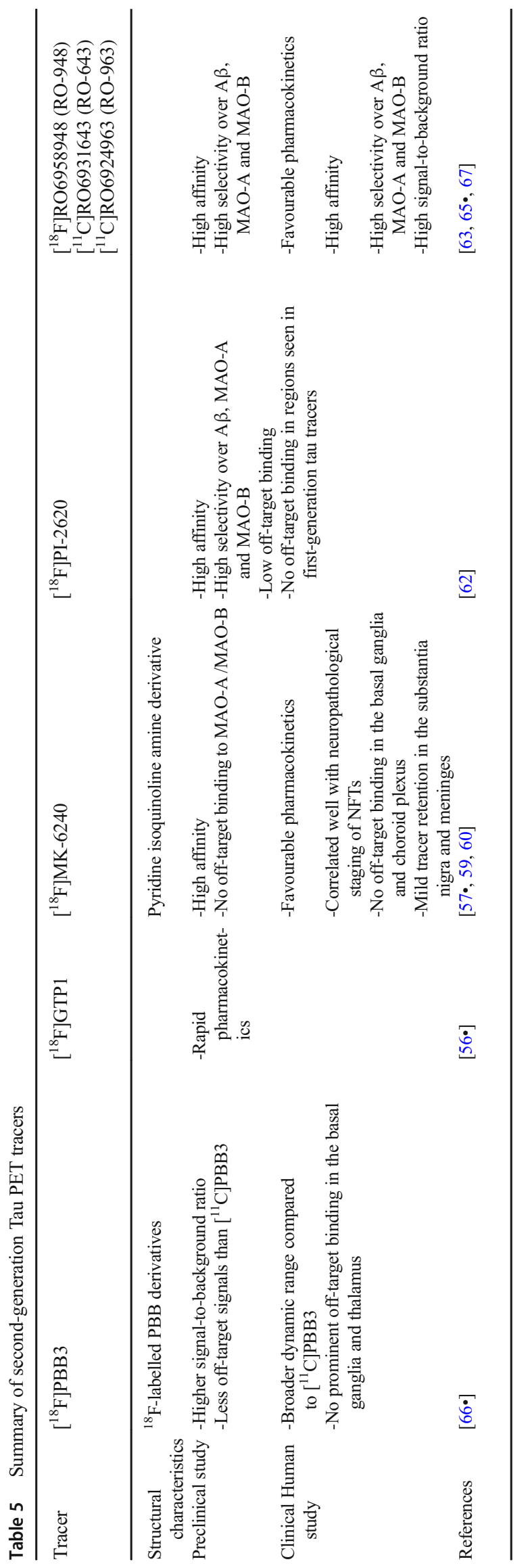


images and a short summary are given in Fig. 6 and Table 5 respectively.

\section{Conclusions and Future Prospects}

The advance in in vivo tau imaging has provided exciting and promising results on the usefulness of tau PET in the research of dementia. In vivo tau imaging combined with amyloid and FDG PET imaging could serve as a promising biomarker both clinically and in research. It can support differential diagnosis and the closer association of tau with cognitive impairment as well as neuronal dysfunction makes it suitable for monitoring disease progression. Moreover, it will help identify suitable patients for clinical trials.

Second-generation tau tracers improved substantially in the binding affinity and selectivity compared to firstgeneration tracers and indeed all these results are leading us onto a new path. However, more in-depth work is still required. Several novel tau tracers are progressing to clinical human studies with results keenly anticipated. In addition, further work involving both tau and $A \beta$ as well as other pathologies, performed at different stages of the disease, will yield more insights into disease pathogenesis. Identification of tau fibril strains accessible to each tau PET ligand would be of critical significance for the use of these tracers to serve as early and differential diagnosis of dementing tauopathies [47•].

In conclusion, tau PET imaging gives a precious opportunity to diagnose dementia accurately, and to evaluate multitargeted therapy much more efficiently.

\section{Compliance with Ethical Standards}

Conflict of Interest Paul Edison was funded by the Medical Research Council and now by Higher Education Funding Council for England (HEFCE). He has also received grants from Alzheimer's Research, UK, Alzheimer's Drug Discovery Foundation, Alzheimer's Society, UK, Novo Nordisk, GE Healthcare, Astra Zeneca, Eli Lilly, Piramal Life Sciences, Avid, Medical Research Council, Van Geest Foundation and Biomedical Research centre. He has also received consultancy and speaker fees from Piramal Life Science and a consultancy fee from Pfizer. Yi Ting Wang declares no potential conflicts of interest.

Human and Animal Rights and Informed Consent This article does not contain any studies with human or animal subjects performed by any of the authors.

Open Access This article is distributed under the terms of the Creative Commons Attribution 4.0 International License (http://creativecom mons.org/licenses/by/4.0/), which permits unrestricted use, distribution, and reproduction in any medium, provided you give appropriate credit to the original author(s) and the source, provide a link to the Creative Commons license, and indicate if changes were made.

\section{References}

Papers of particular interest, published recently, have been highlighted as:

- Of importance

- Of major importance

1. Serrano-Pozo A, Frosch MP, Masliah E, Hyman BT. Neuropathological alterations in Alzheimer disease. Cold Spring Harb Perspect Med. 2011;1:a006189.

2. Brion JP. Neurofibrillary tangles and Alzheimer's disease. Eur Neurol. 1998;40:130-40.

3. Dani M, Edison P, Brooks DJ. Imaging biomarkers in tauopathies. Parkinsonism Relat Disord. 2016;22(Suppl 1):S26-8.

4. Lee VM, Goedert M, Trojanowski JQ. Neurodegenerative tauopathies. Annu Rev Neurosci. 2001;24:1121-59.

5. Delacourte A. Tauopathies: recent insights into old diseases. Folia Neuropathol. 2005;43:244-57.

6. Park SA, Ahn SI, Gallo J-M. Tau mis-splicing in the pathogenesis of neurodegenerative disorders. BMB Rep. 2016;49:405-13.

7. Liu F, Gong C-X. Tau exon 10 alternative splicing and tauopathies. Mol Neurodegener. 2008;3:8.

8. Josephs KA. Current understanding of neurodegenerative diseases associated with the protein tau. Mayo Clin Proc. 2017;92:1291303.

9. Braak H, Braak E. Neuropathological stageing of Alzheimerrelated changes. Acta Neuropathol. 1991;82:239-59.

10. Yeung AWK, Goto TK, Leung WK. The changing landscape of neuroscience research, 2006-2015: a bibliometric study. Front Neurosci. 2017;11:120.

11. Declercq L, Celen S, Lecina J, Ahamed M, Tousseyn T, Moechars $\mathrm{D}$, et al. Comparison of new tau PET-tracer candidates with [18F]T 808 and [18F]T807. Mol Imaging. 2016;15: 153601211562492 .

12. Maruyama M, Shimada H, Suhara T, Shinotoh H, Ji B, Maeda J, et al. Imaging of tau pathology in a tauopathy mouse model and in Alzheimer patients compared to normal controls. Neuron. 2013;79: 1094-108.

13. Chien DT, Bahri S, Szardenings AK, Walsh JC, Mu F, Su M-Y, et al. Early clinical PET imaging results with the novel PHF-tau radioligand [F-18]-T807. J Alzheimers Dis. 2013;34:457-68.

14. Chien DT, Szardenings AK, Bahri S, Walsh JC, Mu F, Xia C, et al. Early clinical PET imaging results with the novel PHF-tau radioligand [F18]-T808. J Alzheimers Dis. 2014;38:171-84.

15.• Harada R, Okamura N, Furumoto S, Furukawa K, Ishiki A, Tomita $\mathrm{N}$, et al. 18F-THK5351: a novel PET radiotracer for imaging neurofibrillary pathology in Alzheimer disease. J Nucl Med. 2016;57: 208-14 First-in-human 18F-THK5351 PET studies in AD patients.

16. Shin J, Kepe V, Barrio JR, Small GW. The merits of FDDNP-PET imaging in Alzheimer's disease. J Alzheimers Dis. 2011;26(Suppl 3): $135-45$.

17. Ossenkoppele R, Tolboom N, Foster-Dingley J, Boellaard R, Yaqub M, Windhorst AD, et al. First ever longitudinal [ 11C ]PIB and [ 18 F]FDDNP PET studies in patients with Alzheimer's disease or mild cognitive impairment and healthy controls. Alzheimers Dement. 2010;6:S72.

18. Wood H. Alzheimer disease: [11C]PBB3-a new PET ligand that identifies tau pathology in the brains of patients with AD. Nat Rev Neurol. 2013;9:599.

19.• Shimada H, Kitamura S, Shinotoh H, Endo H, Niwa F, Hirano S, et al. Association between $A \beta$ and tau accumulations and their influence on clinical features in aging and Alzheimer's disease spectrum brains: a [11C]PBB3-PET study. Alzheimers Dement 
(Amst). 2017;6:11-20 A recent study investigating interactions between $A \beta$ and tau accumulations and their influence on clinical features.

20. Okamura N, Harada R, Furumoto S, Arai H, Yanai K, Kudo Y. Tau PET imaging in Alzheimer's disease. Curr Neurol Neurosci Rep. 2014; $14: 500$.

21. Shah M, Catafau AM. Molecular imaging insights into neurodegeneration: focus on tau PET radiotracers. J Nucl Med. 2014;55:871-4.

22. Okamura N, Suemoto T, Furumoto S, Suzuki M, Shimadzu H, Akatsu $\mathrm{H}$, et al. Quinoline and benzimidazole derivatives: candidate probes for in vivo imaging of tau pathology in Alzheimer's disease. J Neurosci. 2005;25:10857-62.

23. Fodero-Tavoletti MT, Okamura N, Furumoto S, Mulligan RS, Connor AR, McLean CA, et al. 18F-THK523: a novel in vivo tau imaging ligand for Alzheimer's disease. Brain. 2011;134:1089100.

24. Harada R, Okamura N, Furumoto S, Tago T, Maruyama M, Higuchi $\mathrm{M}$, et al. Comparison of the binding characteristics of [18F]THK523 and other amyloid imaging tracers to Alzheimer's disease pathology. Eur J Nucl Med Mol Imaging. 2013;40:125-32.

25. Okamura N, Furumoto S, Harada R, Tago T, Yoshikawa T, FoderoTavoletti M, et al. Novel 18F-labeled arylquinoline derivatives for noninvasive imaging of tau pathology in Alzheimer disease. J Nucl Med. 2013;54:1420-7.

26. Villemagne VL, Furumoto S, Fodero-Tavoletti MT, Mulligan RS, Hodges J, Harada R, et al. In vivo evaluation of a novel tau imaging tracer for Alzheimer's disease. Eur J Nucl Med Mol Imaging. 2014;41:816-26.

27. Okamura N, Furumoto S, Fodero-Tavoletti MT, Mulligan RS, Harada R, Yates P, et al. Non-invasive assessment of Alzheimer's disease neurofibrillary pathology using $18 \mathrm{~F}-\mathrm{THK} 5105$ PET. Brain. 2014;137:1762-71.

28. Harada R, Okamura N, Furumoto S, Furukawa K, Ishiki A, Tomita N, et al. [(18)F]THK-5117 PET for assessing neurofibrillary pathology in Alzheimer's disease. Eur J Nucl Med Mol Imaging. 2015;42: 1052-61.

29. Fodero-Tavoletti MT, Furumoto S, Taylor L, McLean CA, Mulligan RS, Birchall I, et al. Assessing THK523 selectivity for tau deposits in Alzheimer's disease and non-Alzheimer's disease tauopathies. Alzheimers Res Ther. 2014;6:11.

30. Xia C-F, Arteaga J, Chen G, Gangadharmath U, Gomez LF, Kasi D, et al. [(18)F]T807, a novel tau positron emission tomography imaging agent for Alzheimer's disease. Alzheimers Dement. 2013;9: 666-76.

31. Baker SL, Harrison TM, Maass A, La Joie R, Jagust WJ. Explaining [18f]-av-1451 variability in healthy controls across the lifespan. Alzheimers Dement. 2018;14:P3-4 A recent study explaining $\left[{ }^{18} \mathrm{~F}\right] \mathrm{AV}-1451$ variability in healthy subjects across the lifespan.

32. Cha J, Park Y-H, Lee J-M, Baker SL, Visani A, Bourakova V, et al. Modeling amyloid, tau, and neurodegeneration across the alzheimer's disease spectrum: cross-sectional study. Alzheimers Dement. 2018;14:P489.

33. Mattsson N, Ossenkoppele R, Smith R, Strandberg O, Ohlsson T, Jögi J, et al. Greater tau load and reduced cortical thickness in APOE $\varepsilon 4$-negative Alzheimer's disease: a cohort study. Alzheimers Res Ther. 2018;10:77.

34.• Jack CR, Wiste HJ, Schwarz CG, Lowe VJ, Senjem ML, Vemuri P, et al. Longitudinal tau PET in ageing and Alzheimer's disease. Brain. 2018;141:1517-28 Compare different whole-brain and region-specific measurements of within-person change on serial tau PET and evaluate its utility for clinical trials.

35. Pascoal T, Mathotaarachchi S, Chamoun M, Kang MS, Therriault J, Struyfs H, et al. Voxel-wise determination of thresholds and accuracy of [18F]AV1451 and [18F]MK6240 ligands for neurofibrillary tangles. 2018.
36. Zhang W, Arteaga J, Cashion DK, Chen G, Gangadharmath U, Gomez LF, et al. A highly selective and specific PET tracer for imaging of tau pathologies. J Alzheimers Dis. 2012;31:601-12.

37.• Lemoine L, Gillberg P-G, Svedberg M, Stepanov V, Jia Z, Huang J, et al. Comparative binding properties of the tau PET tracers THK5117, THK5351, PBB3, and T807 in postmortem Alzheimer brains. Alzheimers Res Ther. 2017;9:96 A head-to-head study comparing the binding properties of several tau positron emission tomography tracers in the same human brain tissue.

38. Villemagne VL, Furumoto S, Fodero-Tavoletti M, Harada R, Mulligan RS, Kudo Y, et al. The challenges of tau imaging. Future Neurol. 2012;7:409-21.

39. Spillantini MG, Goedert M. Tau pathology and neurodegeneration. Lancet Neurol. 2013;12:609-22.

40. Kikuchi A, Okamura N, Hasegawa T, Harada R, Watanuki S, Funaki Y, et al. In vivo visualization of tau deposits in corticobasal syndrome by 18F-THK5351 PET. Neurology. 2016;87:2309-16.

41. Ng KP, Pascoal TA, Mathotaarachchi S, Therriault J, Kang MS, Shin M, et al. Monoamine oxidase B inhibitor, selegiline, reduces 18F-THK5351 uptake in the human brain. Alzheimers Res Ther. 2017;9:25 Show interpretation of 18F-THK5351 PET images is confounded by the high MAO-B availability across the entire brain.

42. Vermeiren C, Motte P, Viot D, Mairet-Coello G, Courade J-P, Citron $\mathrm{M}$, et al. The tau positron-emission tomography tracer AV1451 binds with similar affinities to tau fibrils and monoamine oxidases. Mov Disord. 2018;33:273-81.

43. Choi JY, Cho H, Ahn SJ, Lee JH, Ryu YH, Lee MS, et al. Off-target $18 \mathrm{~F}-\mathrm{AV}-1451$ binding in the basal ganglia correlates with agerelated iron accumulation. J Nucl Med. 2018;59:117-20.

44. Saint-Aubert L, Lemoine L, Chiotis K, Leuzy A, Rodriguez-Vieitez E, Nordberg A. Tau PET imaging: present and future directions. Mol Neurodegener. 2017;12:19 A recent review on tau PET imaging development.

45.• Okamura N, Harada R, Ishiki A, Kikuchi A, Nakamura T, Kudo Y. The development and validation of tau PET tracers: current status and future directions. Clin Transl Imaging. 2018;6:305-16 A very recent review providing an overview on PET imaging of tau pathology in Alzheimer's disease and other neurodegenerative disorders.

46. Chiotis K, Stenkrona P, Almkvist O, Stepanov V, Ferreira D, Arakawa R, et al. Dual tracer tau PET imaging reveals different molecular targets for 11C-THK5351 and 11C-PBB3 in the Alzheimer brain. Eur J Nucl Med Mol Imaging. 2018;45:1605-17.

47. Ono M, Sahara N, Kumata K, Ji B, Ni R, Koga S, et al. Distinct binding of PET ligands PBB3 and AV-1451 to tau fibril strains in neurodegenerative tauopathies. Brain. 2017;140:764-80 Highlight the more robust ability of $\mathrm{PBB3}$ to capture wide-range tau pathologies.

48. Jang YK, Lyoo CH, Park S, Oh SJ, Cho H, Oh M, et al. Head to head comparison of $[18 \mathrm{~F}] \mathrm{AV}-1451$ and $[18 \mathrm{~F}]$ THK 5351 for tau imaging in Alzheimer's disease and frontotemporal dementia. Eur J Nucl Med Mol Imaging. 2018;45:432-42.

49. Hahn A, Schain M, Erlandsson M, Sjölin P, James GM, Strandberg OT, et al. Modeling strategies for quantification of in vivo 18F-AV1451 binding in patients with tau pathology. J Nucl Med. 2017;58: 623-31.

50. Smith R, Puschmann A, Schöll M, Ohlsson T, van Swieten J, Honer $\mathrm{M}$, et al. 18F-AV-1451 tau PET imaging correlates strongly with tau neuropathology in MAPT mutation carriers. Brain. 2016;139: 2372-9.

51. Schöll M, Ossenkoppele R, Strandberg O, Palmqvist S, Swedish BioFINDER study, Jögi J, et al. Distinct 18F-AV-1451 tau PET retention patterns in early- and late-onset Alzheimer's disease. Brain. 2017;140:2286-94. 
52. Mattsson N, Schöll M, Strandberg O, Smith R, Palmqvist S, Insel PS, et al. 18F-AV-1451 and CSF T-tau and P-tau as biomarkers in Alzheimer's disease. EMBO Mol Med. 2017;9:1212-23 Elucidate the relationship between cerebrospinal fluid, total-tau and phosphorylated tau with the tau PET ligand 18F-AV-1451 in Alzheimer's disease.

53. Smith R, Schain M, Nilsson C, Strandberg O, Olsson T, Hägerström D, et al. Increased basal ganglia binding of $18 \mathrm{~F}-\mathrm{AV}$ 1451 in patients with progressive supranuclear palsy. Mov Disord. 2017;32:108-14 Characterise the tracer uptake of $\left[{ }^{\mathbf{1 8}} \mathbf{F}\right] \mathbf{A V}$ 1451 in progressive supranuclear palsy.

54. Smith R, Schöll M, Honer M, Nilsson CF, Englund E, Hansson O. Tau neuropathology correlates with FDG-PET, but not AV-1451PET, in progressive supranuclear palsy. Acta Neuropathol. 2017;133:149-51.

55. Smith R, Schöll M, Widner H, van Westen D, Svenningsson P, Hägerström D, et al. In vivo retention of $18 \mathrm{~F}-\mathrm{AV}-1451$ in corticobasal syndrome. Neurology. 2017;89:845-53 Characterise the tracer uptake of $\left[{ }^{18} \mathrm{~F}\right] \mathrm{AV}-1451$ in corticobasal syndrome.

56. Bohorquez SS, Barret O, Tamagnan G, Alagille D, Marik J, Ayalon $\mathrm{G}$, et al. Evaluation of tau burden in a cross-sectional cohort of Alzheimer's disease subjects using [18f]gtp1 (genentech tau probe 1). Alzheimers Dement. 2016;12:P1172 First-in-human PET study of $\left[{ }^{18}\right.$ F]GTP1.

57. Walji AM, Hostetler ED, Selnick H, Zeng Z, Miller P, Bennacef I, et al. Discovery of 6-(Fluoro-(18)F)-3-(1H-pyrrolo[2,3-c]pyridin-1yl)isoquinolin-5-amine ([(18)F]-MK-6240): a positron emission tomography (PET) imaging agent for quantification of neurofibrillary tangles (NFTs). J Med Chem. 2016;59:4778-89 First literature describing [(18)F]-MK-6240.

58. Pascoal TA, Shin M, Kang MS, Chamoun M, Chartrand D, Mathotaarachchi S, et al. In vivo quantification of neurofibrillary tangles with [18F]MK-6240. Alzheimers Res Ther. 2018;10:74.

59. Hostetler ED, Walji AM, Zeng Z, Miller P, Bennacef I, Salinas C, et al. Preclinical characterization of $18 \mathrm{~F}-\mathrm{MK}-6240$, a promising PET tracer for in vivo quantification of human neurofibrillary tangles. J Nucl Med. 2016;57:1599-606.

60. Betthauser TJ, Cody KA, Zammit MD, Murali D, Converse AK, Barnhart TE, et al. In vivo characterization and quantification of neurofibrillary tau PET radioligand [18F]MK-6240 in humans from Alzheimer's disease dementia to young controls. J Nucl Med. 2018;60:93-9.

61. Stephens A. Characterization of novel PET tracers for the assessment of tau pathology in AD and other tauopathies. 2017.

62. Barret O. First in human characterization of PI-2620, a next generation PET tracer for assessing tau in $\mathrm{AD}$ and other tauopathies. 2017.

63. Honer M, Gobbi L, Knust H, Kuwabara H, Muri D, Koerner M, et al. Preclinical evaluation of 18F-RO6958948, 11C-RO6931643, and 11C-RO6924963 as novel PET radiotracers for imaging tau aggregates in Alzheimer disease. J Nucl Med. 2018;59:675-81.

64. Gobbi LC, Knust H, Körner M, Honer M, Czech C, Belli S, et al. Identification of three novel radiotracers for imaging aggregated tau in Alzheimer's disease with positron emission tomography. J Med Chem. 2017;60:7350-70.

65. Wong DF, Borroni E, Kuwabara H, George N, Rosenberg PB, Lyketsos C, et al. First in-human PET study of 3 novel tau radiopharmaceuticals: [11C]RO6924963, [11C]RO6931643, and [18F]RO6958948. Alzheimers Dement. 2015;11:850-1 First inhuman PET study of [11C]RO6924963, [11C]RO6931643 and [18F]RO6958948.

66. Shimada H, Kitamura S, Ono M, Kimura Y, Ichise M, Takahata K, et al. First-in-human pet study with $18 \mathrm{f}$-am-pbb3 and $18 \mathrm{f}-\mathrm{pm}-$ pbb3. Alzheimers Dement. 2017;13:P146 First-in-human PET study of $\left[{ }^{18} \mathrm{~F}\right] \mathrm{PBB} 3$.

67. Kuwabara H, Comley RA, Borroni E, Honer M, Kitzmiller K, Roberts J, et al. Evaluation of 18F-RO-948 (18F-RO6958948) for quantitative assessment of tau accumulation in the human brain with positron emission tomography. J Nucl Med. 2018;59:187784.

Publisher's Note Springer Nature remains neutral with regard to jurisdictional claims in published maps and institutional affiliations. 